\title{
EL DERECHO Y LA OBLIGACIÓN DE VOTAR
}

\author{
Pablo Marshall Barberán*
}

\begin{abstract}
RESUMEN
Este artículo discute acerca de la reforma al sistema de sufragio actualmente establecido en la Constitución y que se encuentra ad portas de ser modificado. Se revisa, en la primera parte, la cuestión conceptual acerca del carácter normativo que tiene y debe tener el voto, fundado en la premisa de que es un derecho y no una obligación. Se concluye, empero, que no existe contradicción conceptual en la figura del derecho de ejercicio obligatorio. Luego, en la segunda parte, se revisa, más superficialmente, la argumentación que ha sido llevada a cabo para justificar la necesidad del cambio de régimen de sufragio, concluyéndose que las razones de principio que deben estar en la base de una decisión de ese tipo no han sido explicitadas.
\end{abstract}

\section{DERECHO A SUFRAGIO - SUFRAGIO OBLIGATORIO - REFORMA CONSTITUCIONAL}

\section{The right and the duty to vote}

\section{Abstract}

This article deals with the suffrage system reform being attemted at the present. In the first part the conceptual matter referring to the normative character that the act of voting possesses and must possess is revised, assuming the premise that it is a right and not an obligation. It is concluded that there is no conceptual contradiction in the figure of a right which exercise is mandatory. In the second part, the arguments used to justify the need to reform the suffrage regime are revised, concluding that the principle reasons that should be on the base of this kind of decision have not been explicit.

\section{RIGHT TO SUFFRAGE - MANDATORY SUFFRAGE - CONSTITUTIONAL REFORM}

* Abogado, Profesor de Derecho Constitucional, Universidad Austral de Chile, Valdivia, Chile. pmarshall@uach.cl. El autor agradece a los abogados Mary Paz Muñoz y Guillermo Jiménez por sus valiosos comentarios. Artículo recibido el 27 de marzo de 2009 y aceptado para su publicación por el Comité Editorial el 18 de mayo de 2009. 


\section{INTRODUCCIÓN}

$\mathrm{E}$ 111 de marzo de 2009 se terminó la tramitación ante el Congreso de la reforma constitucional "que modifica los artículos 15 y 18 de la Carta Fundamental, con el objeto de consagrar el sufragio como un derecho de los ciudadanos y de su inscripción automática en los Registros Electorales”. El proyecto aprobado por ambas Cámaras fue remitido para que el Presidente de la República proceda a su sanción y promulgación. ${ }^{1}$ En dicho proyecto se cambia expresamente el estatus del voto en la Constitución de obligatorio a voluntario. No obstante aquello, subsisten las dudas sobre el destino del proyecto, en la medida que no existe un acuerdo definitivo respecto al régimen de padrón electoral, lo que se traduce en un desacuerdo en torno a las fórmulas de inscripción automática y a la posibilidad de desinscripción.

A propósito de esta noticia, vuelve a presentarse la posibilidad de discutir las ideas que, más o menos abiertamente, están involucradas en la pregunta sobre qué régimen de sufragio Chile necesita.

Son muchos e interesantes los temas que respecto al régimen electoral en general y del régimen del sufragio en particular pueden analizarse. Sin embargo, al revisar las publicaciones que han tematizado estas cuestiones parece importante llamar la atención sobre lo que no se dijo, más que sobre lo que se dijo, se hayan o no logrado acuerdos o llegado a consensos. ${ }^{2}$ Así, el presente artículo pretende revisar dos cuestiones que a primera vista no parecen problemáticas, y por cierto no parecieron problemáticas ni en la discusión pública ni en el debate parlamentario. Ellas son, por un lado, el significado del carácter de derecho que tiene el voto y, por otro, el significado normativo que tendría una reforma en relación a la obligatoriedad o voluntariedad del voto, más allá, claro, de las consideraciones estratégicas relativas a la finalidad de la implementación de la reforma constitucional y la posterior, y aún incierta, reforma legal. ${ }^{3}$

Sobre este último punto, puede sorprender que el acuerdo entre el Gobierno y oposición haya sido logrado en relación a la reforma constitucional y no, todavía, en torno a una reforma legal. Ello constata una ya larga tradición, durante los gobiernos de la Concertación, de reformas constitucionales que no denotan acuerdos de principios sobre las cuestiones constitucionales involucradas y que sólo cumplen el rol de compromisos, que diluyen la toma de las decisiones en la discusión de la reforma legal. ${ }^{4}$ En ese sentido, la Constitución Política parece no ser tomada demasiado en serio, como aquella norma

${ }^{1}$ Véase, Boletín 3544-07.

${ }^{2}$ Por ejemplo, puede consultase Fontaine, A. et al. (eds.), Modernización del Régimen Electoral Chileno PNUD, Santiago, 2007; Fuentes y Villar (eds.), Voto Ciudadano. Debate sobre la Inscripción Electoral FLACSO, Santiago, 2005; Huneeus, C. (ed.), La Reforma el Sistema Binominal en Chile. Propuestas para el Debate, Catalonia, Santiago, 2006.

${ }^{3}$ El Gobierno relanzó el proyecto de reforma legal, que incorpora reformas en el régimen de inscripción electoral, mediante un menaje en el Boletín 6418-07, que viene a refundir y replantear los proyectos de ley anteriores sobre este particular (véanse boletines 3586-06, 3936, 268-07).

${ }^{4}$ Sobre la noción de compromisos constitucionales, véase Schmitt, C., Teoría de la Constitución, Alianza, Madrid, 1983, pp. 52-5. 
suprema donde se plasman las decisiones fundamentales del pueblo en relación a la configuración de la vida estatal. Parece ir paulatinamente cobrando fuerza la idea, señalada por Eduardo Aldunate a propósito de las reformas constitucionales del año 2005, que la Constitución se ha transformado en una cuestión de poca importancia. ${ }^{5}$

\section{Problemas CONCEPTUALES EN TORNO AL SUFRAgio}

Tanto "Participación electoral obligatoria: una defensa" de Tomás Chuaqui como "El voto como derecho: una cuestión de principios" de Lucas Sierra discuten sobre el estatus deontológico del voto. En sus términos, discuten acerca de si el voto es un derecho o una obligación. Las argumentaciones de ambos son muy complejas e interesantes, pero ambas aparecen como demasiado filosóficas. Parece que haciendo alguna aclaración, se ahorrarían varias de las polémicas que parecen finalmente infructuosas, en especial aquellas referidas al problema de diferenciar lo que el voto es de lo que éste debe ser.

En el caso de las dos investigaciones citadas, parece ser una premisa aceptada que la obligatoriedad del voto es una cuestión, en algún sentido determinante, normativa. Existe también acuerdo en que la conveniencia de la obligatoriedad del voto es una cuestión que está sujeta a una discusión en la que caben tanto argumentos normativos como argumentos estratégicos u orientados a las consecuencias. Todo ello hace conveniente recordar que cuando se discute un tema como éste los discursos normativos y los discursos estratégicos deben ser distinguidos, de lo contrario el riesgo de malos entendidos, equivocaciones o, lo que es peor, trampas argumentativas, siempre se mantendrá. Ordenar la discusión es necesario cuando se confunden o se intentan presentar de manera conjunta o indiferenciada argumentos normativos con argumentos estratégicos.

La idea central que se pretende plantear en este artículo es que tanto Sierra como Chuaqui yerran al concebir que el carácter de derecho que pueda tener el sufragio determina la naturaleza obligatoria o voluntaria del mismo. Si bien ambos autores defienden la implementación de distintas medidas, fundadas en distintas concepciones del rol de la comunidad política, ambos parten de la base de que hay argumentos trascendentales que obligan a elegir entre el voto voluntario u obligatorio. Sin embargo, si se entiende que la naturaleza jurídica del derecho a voto nada dice sobre la obligatoriedad o voluntariedad de su ejercicio, pueden redireccionarse algunos de los argumentos trascendentales y enfocarlos en la argumentación respecto a la conveniencia y necesidad de una vida política y democrática más robusta. El hacer menos existencial la discusión, esto es, considerar que la obligatoriedad o voluntariedad del voto no viene necesariamente exigida directamente por teorías respecto a la naturaleza y el rol de la comunidad política, la sociedad y el Estado, permite, quizás, evaluar mejor los argumentos en pro y en contra del voto obligatorio.

${ }^{5}$ Aldunate, E., "El fin de la transición. Hacia una Constitución de poca importancia. Visión crítica de la reforma de la Ley No 20.050”, en Zúñiga, F., Reforma Constitucional, Ed. LexisNexis, Santiago, 2005. 
En su artículo, Lucas Sierra ha sostenido que "convertir" el derecho a votar en un deber de votar es perjudicial por razones de principio. ${ }^{6}$ Esta afirmación plantea varias cuestiones interesantes. En primer lugar, surge la pregunta relativa a si el voto es efectivamente un derecho y, en esa hipótesis, qué es lo que eso significa. En segundo lugar, se advierte sobre la necesidad de determinar si no existen otras posiciones jurídicas que se entrelazan con el derecho a voto, particularmente si existe la obligación de votar. Sin embargo, antes de desarrollar un análisis sobre estos temas se dará un vistazo a un buen esquema de posiciones deónticas en las que puede encontrarse una persona. Dicho esquema permite una mayor claridad y rigor analítico en cuestiones normativas. Como propuso su autor:

Uno de los obstáculos mayores a la comprensión clara, enunciación aguda y solución verdadera de los problemas jurídicos, surge con frecuencia de la suposición expresa o tácita de que las relaciones jurídicas pueden ser reducidas a derechos y deberes, y de que estas últimas categorías son, por lo tanto, adecuadas para analizar los intereses jurídicos más complicados [...] porque en cualquier problema jurídico como de otro tipo, las palabras "camaleón" constituyen un peligro tanto para el pensamiento claro, como para la expresión lucida. ${ }^{7}$

\section{Derechos, deberes, privilegios y no-derechos}

El artículo de Hohfeld sobre los conceptos jurídicos fundamentales es quizás una de las más influyentes obras sobre el concepto de derecho en su sentido subjetivo. Hohfeld escribe su obra preocupado de la multitud de posiciones y situaciones que se ven etiquetadas con el equívoco rótulo de "derecho" y se esfuerza en distinguir analíticamente cuáles son esas posiciones. De esta manera, este autor compone un cuadro de relaciones jurídicas diferentes (opuestas y correlativas) mediante las cuales dos o más sujetos pueden estar vinculados. Este cuadro de posiciones permite distinguir qué es lo que debe o no debe hacer el sujeto involucrado en la posición jurídica.

Para lo que nos interesa aquí, Hohfeld esclarece el contenido de concepto de derecho subjetivo asignándole un significado claro e inequívoco. Presenta al derecho subjetivo como una posición en la que un sujeto $(\mathrm{X})$ se encuentra respecto de otro $(\mathrm{Y})$ en una posición de exigir que éste $(\mathrm{Y})$ realice una acción o abstención y ese otro sujeto (Y) tiene un obligación o deber para con el primero (X) de realizar la acción abstención a que el primero $(\mathrm{X})$ tiene derecho. Por ejemplo, el profesor tiene un derecho respecto del ayudante, si es el caso que el profesor puede exigir al ayudante que haga una clase. El

${ }^{6}$ Sierra, L., "El voto como derecho: una cuestión de principios", en op. cit. en nota 2, pp. 166-9.

${ }^{7}$ Hohfeld, W. N., Conceptos Jurídicos Fundamentales, Centro Editor de América Latina, Buenos Aires, 1968, pp. 45-6. 
ayudante se encuentra obligado con el profesor a realizar la clase y el profesor tiene un derecho respecto del ayudante a que éste realice la clase. ${ }^{8}$

Como la posición jurídica opuesta al deber se ubica la libertad (o privilegio en términos de Hohfeld). La libertad es aquella posición en la cual se niega la existencia de un deber. Un sujeto $(\mathrm{X})$ es libre cuando no está obligado a realizar (o abstenerse de realizar) una conducta determinada. Esta posición tiene como correlato un no-derecho, esto es, quien tiene un no-derecho (Y) se encuentra en una posición de no poder exigir que realice una acción u omisión al privilegiado $(\mathrm{X})$, a diferencia de lo que puede exigir quien tiene un derecho a quien tiene el deber correlativo. Volviendo sobre el ejemplo anterior, si el profesor tiene la libertad de ir a la clase que debe realizar su ayudante, su ayudante o (el decano) tiene un no-derecho a exigirle al profesor que vaya o no vaya a la clase, esto es, no puede obligar al profesor a que concurra o falte a la clase, porque no tiene ningún derecho sobre él. Así, el cuadro completo se compone de un derecho del profesor a que el ayudante haga la clase y una libertad de ir o no a la clase. El estudiante, por otro lado, no puede exigirle al profesor que vaya o no vaya a la clase (no-derecho) que él está obligado respecto de aquél a realizar (deber).

Tener un deber es sustancialmente distinto a no tener un derecho (o tener un noderecho), tener una libertad o privilegio es sustancialmente distinto que tener un derecho. Derecho y libertad, entonces, son posiciones en las que se encuentran los sujetos que son diferentes una de otra. Ello implica, para este trabajo, que una acción puede ser objeto de un derecho y no ser objeto de una libertad o, por el contrario, puede ser objeto de una libertad y no ser objeto de un derecho. Para considerar el primer caso, puede proponerse otro ejemplo, esta vez más jurídico.

En el derecho de familia tradicionalmente se habla de derechos-deberes cuando se hace referencia a las relaciones que se generan entre los hijos y los padres. Lo que tradicionalmente se ha denominado derecho-deber en derecho de familia tiene un símil con el derecho a voto. Tómese el ejemplo del derecho-deber del padre respecto del hijo de mantener una relación directa y regular, lo que anteriormente solía llamarse "visitas". El contenido del tal derecho-deber es, por un lado, un deber del padre o madre que no viven con su hijo de frecuentarlo efectivamente. Este deber tiene su correlato en el derecho del hijo de ser frecuentado, conocer y compartir cotidianamente con su padre. Hasta allí sólo se ve una obligación del padre, sin embargo, tal obligación coexiste con un derecho del padre. El padre o madre tiene un derecho a mantener una relación directa

${ }^{8}$ La cuestión central para determinar si existe un derecho es si existe un deber correlativo. No hay un derecho sin un deber correlativo. Sin embargo, no siempre donde hay un deber hay un derecho subjetivo correlativo, existen obligaciones que emanan del ordenamiento jurídico objetivo. Reducir esas obligaciones o deberes legales a una relación entre dos sujetos no parece del todo correcto. Puede tomarse el ejemplo de los deberes de conducta emanados de la regulación penal. Entre el destinatario de una norma penal que prohíbe matar a otro y la potencial víctima de dicho homicidio no parece haber una relación explicable por la titularidad de un derecho y un deber correlativo. Tampoco parece correcto pensar en el Estado como el titular del derecho correlativo al deber de no matar a otro. La obligación de no matar a otro parece ser una "obligación no relacional". Véase, al respecto, Alexy, R., Teoría de los derechos fundamentales, Centro de Estudios Constitucionales, Madrid, 1993, p. 202. 
y regular con su hijo. Tiene un derecho a que no se le prohíba o impida tener tal relación 9 . Tal derecho del padre o madre tiene un destinatario indeterminado. En realidad, pueden pensarse varios destinatarios, por ejemplo, (a) el otro padre o madre quien tiene a su cuidado al hijo, (b) el Estado, (c) lo Tribunales de Justicia, (d) otros parientes que tengan el cuidado personal del menor, etcétera. En suma, la relación directa y regular del padre y el hijo es un derecho de ejercicio obligatorio. Nadie puede exigir al padre que deje de mantener relación con su hijo, pero el padre debe mantener relación con su hijo, y en este sentido, no es libre para decidirlo.

Si pueden existir derechos obligatorios, ¿podrán existir libertades que no sean derechos? Los casos más vistosos de libertades jurídicas son libertades protegidas por un derecho, por ejemplo, la libertad de conciencia (art. $19 \mathrm{n}^{\circ} 6 \mathrm{CPol}$ ) o la libertad de expresión (art. $19 \mathrm{n}^{\circ} 12 \mathrm{CPol}$ ), ambos sitúan a su titular en una posición en la cual es libre para opinar o creer distintas cosas. Dicha libertad está protegida con un derecho que se dirige al Estado y que exige de éste que no interfiera con esa libertad. En consecuencia, el Estado tiene un deber de no intervención. De esta manera, la libertad de culto, que puede expresarse como la ausencia del deber de pertenecer a un culto, existiendo así la posibilidad de optar entre dos o más cultos, no implica que el Estado no pueda, por ejemplo, entorpecer el ejercicio de algún culto. Sólo mediante la introducción de un derecho frente al Estado a que éste no realice acciones que tiendan a mermar mi libertad de culto, las alternativas de acción quedan garantizadas frente a la intervención de un tercero, en el caso del derecho fundamental a la libertad de culto, del Estado. Sin embargo, pueden encontrarse importantes casos de libertades no protegidas por un derecho. ${ }^{10}$

La libertad de los padres de elegir el establecimiento educacional de sus hijos no parece estar protegida con un derecho. Cuando una pareja elige libremente el establecimiento educacional de su hijo, esto es, sin un deber de colocar a su hijo, por ejemplo, en el establecimiento educacional primario de su localidad, no por eso tiene garantizado el acceso de su hijo a la educación de su elección. Ello tiene su explicación en que los establecimientos educacionales, al menos gran parte de ellos, no tienen un deber de aceptar a todo niño cuyos padres los eligen o prefieren. Existe un no-derecho de los padres respecto de los establecimientos educacionales y en ese sentido una libertad para la institución de aceptar o no las postulaciones de los candidatos. ${ }^{11}$ Así, la libertad de elegir el establecimiento de sus hijos, no es respecto de los padres, una libertad protegida por derecho, sino que una simple libertad no protegida o una libertad desnuda. ${ }^{12}$

${ }^{9}$ Sobre esta cuestión en el derecho chileno, véase Ramos, R., Derecho de Familia, Ed. Jurídica de Chile, Santiago, 2005, pp. 429ss.

${ }^{10}$ Sobre las libertades protegidas y las libertades no protegidas en el ámbito del derecho constitucional, véase Alexy, R., op. cit. en nota 8, pp. 218ss.

${ }^{11}$ Parece ser que esta es un regulación que será modificada por la nueva Ley General de Educación, que se encuentra en actual tramitación en el Congreso Nacional.

12 Sobre este tema, la interesante propuesta de Atria, F., Mercado y Ciudadanía en la Educación, Ed. Flandes Indiano, Santiago, 2007. El trabajo de Atria sirvió como inspiración para el desarrollo de esta sección del presente artículo. 


\section{2. ¿Un derecho o una libertad?}

Una vez que se tiene clara la distinción de Hohfeld entre derecho y libertad, parece que puede examinarse con una herramienta conceptual útil la discusión sobre el voto. Lucas Sierra plantea en su artículo que habría algunas consecuencias perjudiciales en mutar el carácter de derecho del voto transformándolo en un deber:

Pero lo que no puede haber es un deber jurídico de votar, pues, [... el deber jurídico hace mutar el carácter normativo del voto como derecho, transformándolo en un deber. Esto, además de contrariar el origen histórico liberal del derecho a voto, arriesga peligrosas consecuencias político-constitucionales. Si es un deber, el poder del soberano aumenta enormemente sobre los ciudadanos. Si es un derecho, en cambio, no. ${ }^{13}$

Los problemas que diagnostican estas líneas son dos y es importante separarlos. En primer lugar, está el problema del origen histórico. Contrariar la supuesta tradición histórica del voto no parece plantear problemas de peso. Hay muchas tradiciones que no por la razón de ser tales merecen ser perpetuadas, ya sea porque nunca fueron buenas, ya sea porque ya no existen buenas razones para mantenerlas. La apelación a la tradición liberal del voto requiere de argumentos adicionales. No es claro que el derecho a voto tenga sus únicos antecedentes en la tradición liberal. Si es que se puede remontar la distinción a sus orígenes, la tradición republicana también reclamará esa paternidad. Sin embargo, este no es lugar para sostener esa discusión.

Dejando de lado el primer problema, el peligro constitucional que se menciona requiere más atención. La argumentación continúa de la siguiente manera:

Frente al voto, el soberano puede llegar a tener un conflicto de interés, ya que el ejercicio del voto puede significar la pérdida de su poder, de su calidad de soberano. Por esta razón, es doblemente necesario considerar el voto como un derecho. No vaya a ser cosa que, ante la amenaza de perder las elecciones, el soberano nos exima del "deber" de votar, como puede eximirnos de pagar un impuesto. ${ }^{14}$

El problema de la argumentación de Sierra es que no distingue si está hablando de un derecho o de una libertad, en el sentido que Hohfeld ha propuesto y que aquí se pretende utilizar para evaluar el argumento de Sierra.

Se intuye que al utilizar la expresión derecho, Sierra la considera equivalente a la expresión libertad. Esto, como pudo verse más arriba, es -a lo menos- inexacto. Un derecho es una herramienta ofensiva, tengo derecho a que otro haga o deje de hacer algo. La libertad es una herramienta defensiva, me encuentro en una posición en que

\footnotetext{
${ }^{13}$ Sierra, L., op. cit. en nota 6, p. 167.

${ }^{14}$ Ibid, pp. 167-8.
} 
nadie puede obligarme a hacer o abstenerme de hacer algo, esto es igual a: nadie tiene un derecho respecto de mí. Así las cosas, puede comprenderse que la libertad no sirve para que otros hagan cosas para mí, sino que sólo sirve para que otros no me obliguen a hacer cosas para ellos. Si el voto fuera sólo una libertad, el Estado no estaría forzado a realizar elecciones, no tendría que crear los mecanismos para inscribir candidatos y todas las prestaciones que el Estado está obligado a realizar están fundadas en que los ciudadanos tenemos un derecho a votar.

Sin embargo, existe otra posibilidad para entender lo que Sierra quiere decir con que el voto es un derecho. Puede querer decir que el voto es un derecho (en sentido hohfeldiano) y una libertad al mismo tiempo. Esto es, que el Estado está obligado a realizar todas las acciones necesarias para permitir que los ciudadanos podamos votar, porque tenemos un derecho contra el Estado para ello y, además, que los ciudadanos estamos en una posición en la cual nadie puede exigirnos votar o abstenernos de votar, porque tenemos una libertad de votar.

La primera hipótesis interpretativa de la expresión derecho en el párrafo citado tiene el defecto de hacer que el argumento planteado por Sierra parezca abiertamente incoherente y absurdo. Si sólo tenemos una libertad de votar y no un derecho, entonces ya estamos a merced del Estado. Volver el voto una obligación no posicionaría a los ciudadanos en una peor situación frente al Estado.

La segunda hipótesis interpretativa planteada, que considera que un derecho es una posición de derecho-libertad, no parece ser lo suficientemente articulada, cuando justamente lo que se está discutiendo es el status normativo del sufragio. En consecuencia, se advierte que puede pensarse mejor la cuestión del sufragio obligatorio si se separan estos conceptos que no parecen ir de la mano como la segunda hipótesis de lectura de Sierra parece exigir. Si el derecho-libertad de votar se transforma en un derecho-obligación el Estado no se va a encontrar en una posición de poder "eximir" a los ciudadanos de votar, porque los ciudadanos seguirán teniendo un derecho a votar frente al Estado. Que el Estado tenga un derecho a que los ciudadanos voten es igual a que el voto sea obligatorio, y no habilita al Estado a condonar, perdonar o "eximir" a los ciudadanos de votar. Eso sería desconocer que el voto es un derecho que obliga al Estado y que éste no puede, lícitamente, desconocer ese deber de abstenerse de entorpecer y de proveer todo lo necesario para el ejercicio del sufragio. Que el derecho deba ser una libertad y no una obligación puede fundarse en otras consideraciones, pero no puede fundarse en que el voto sea $-\mathrm{y}$ todos estemos de acuerdo en que así debe ser- un derecho.

\section{Recapitulación}

El derecho a voto, si lo comprendemos así, sólo como un derecho, es una relación en la cual los ciudadanos pueden obligar al Estado a que éste haga todo lo necesario para que ellos puedan votar, incluyendo no impedirles de forma alguna realizar el acto del sufragio. Si, por el contrario, el voto no fuera un derecho de los ciudadanos, esto es, fuera un no-derecho, el Estado no estaría obligado a realizar esas prestaciones ni a abstenerse de esa intervención. 
Por otro lado, el voto puede ser, al mismo tiempo que derecho o no-derecho, libre u obligatorio. Si el voto es una libertad, los ciudadanos pueden votar o no votar. Por el contrario, si el voto es un deber, los ciudadanos sólo pueden votar.

Si concebimos al voto como un derecho y una libertad, nos encontraremos en una posición en la que el Estado está siempre obligado a realizar las prestaciones electorales señaladas y los ciudadanos, por otro lado, pueden o no sufragar, según sea su voluntad. El ciudadano no tiene deberes. Si, por el contrario, concebimos al voto como un derecho y una obligación, el Estado está obligado a realizar prestaciones y abstenciones electorales y el ciudadano está también obligado a sufragar. En este modelo, tanto el Estado y los ciudadanos están obligados.

Los supuestos en que el ciudadano tiene un no-derecho respecto del Estado parecen ser menos interesantes y plausibles en una democracia moderna. En estos casos, si se establece el ejercicio obligatorio del sufragio, la realización de la elección dependerá potestativamente del Estado; si, por el contrario, se establece una libertad de votar, el acto del sufragio dependerá de la contingencia de que la voluntad estatal y la voluntad ciudadana concurran.

No parece haber duda sobre el hecho de que el sufragio es un derecho. Nadie se toma en serio a quien sostenga que es un no-derecho. Todas las miradas deben volverse a la determinación de si el sufragio es una libertad o una obligación, y sobre cuáles son las buenas razones hay para afirmar una u otra cosa.

Si todos podemos estar de acuerdo en que, en primer lugar, el voto es un derecho $y$, en segundo lugar, sobre que nuestro desacuerdo trata sobre si el sufragio es o debe ser libre u obligatorio, estamos en muy buen pie para continuar discutiendo sobre las consecuencias normativas que produciría una reforma en la regulación del derecho a sufragio, como la recientemente aprobada por el Congreso.

\section{El SUFRAGIO EN EL DERECHO CHILENO}

\section{El voto en el derecho chileno: estado actual y reformas}

La Constitución instituye el derecho a voto o sufragio en su artículo 13, que establece también quiénes son ciudadanos y qué derechos otorgan tal calidad. El derecho a sufragio es, en principio, un derecho de quien tiene la titularidad de la ciudadanía. ${ }^{15}$ Luego, en el artículo 15 se establecen las características del voto:

En las votaciones populares, el sufragio será personal, igualitario y secreto. Para los ciudadanos será, además, obligatorio.

${ }^{15}$ Es forzoso concluir eso en la medida que sólo existen dos categorías de individuos con derecho a voto, ciudadanos y extranjeros avecindados. Existen excepciones a esta atribución. El derecho a sufragio puede ser ejercido por extranjeros avecindados en Chile por más de 5 años. Por, otro lado, ciertos ciudadanos pueden tener suspendido el derecho a sufragio. Otra cuestión problemática es la titularidad del derecho a sufragio de aquellos ciudadanos que no se encuentran inscritos en los registros electorales. 
De la disposición transcrita puede concluirse que el estatus deontológico del voto en la Constitución Política es claro. El voto es un derecho (art. 13 inc. $2^{\circ}$ ) y su ejercicio es obligatorio (art. 15 inc. $1^{\circ}$ ). Lo que era posible en la teoría, como se defendió en la primera parte del artículo, es real en la Constitución de Chile. La consideración de que la obligatoriedad del voto está establecida sólo para los ciudadanos tiene una doble función. Por un lado, excluye de la obligatoriedad a aquellas personas que no son ciudadanos, esto es, de los extranjeros con derecho a voto. ${ }^{16}$

Por otro lado, al señalar que el sufragio es una obligación para los ciudadanos, la Constitución cumple la función de poner de relieve el contenido ético de la calidad de ciudadano, como forma de vinculación del individuo a la comunidad política en que está inserto. Que sea conveniente tener dicha disposición si es que no estamos de acuerdo en las razones de principio que existen para mantenerla, es sin duda una buena razón para intentar removerla de la Constitución. Pero parece ser que tal modificación tiene que ser tomada con total conciencia de que el derecho a voto es, en nuestra Constitución, obligatorio. Que el derecho a voto deba ser libre o voluntario parece ser el objetivo de una reforma fundada en un desacuerdo con las razones de principio que subyacen al voto obligatorio actualmente establecido. ${ }^{17}$

\section{Reformas al derecho a voto}

La reforma aprobada por el Congreso Nacional y pendiente ante el Presidente de la República modifica la Constitución de la siguiente manera: sustituye la norma que establece que el voto será obligatorio para los ciudadanos, por una que prescribe la voluntariedad de aquél. El inciso $2^{\circ}$ del artículo 15 pasa a ser el $3^{\circ}$ y se intercala un nuevo inciso $2^{\circ}$ que establece una remisión a la ley para que consagre un sistema de inscripción automática $^{18}$. Así, el proyecto parece decidido a remplazar la actual fórmula de inscripción voluntaria, que relativiza el régimen obligatorio de sufragio. Sin embargo, como se señaló antes, esta reforma constitucional es solamente un compromiso para solucionar el desacuerdo político respecto al sistema de inscripción en la discusión del proyecto de ley orgánica constitucional respectivo. Así, el proyecto de reforma establece en la Constitución Política la disposición transitoria vigesimotercera:

Las reformas introducidas a los artículos 15 y 18 sobre voluntariedad del voto e incorporación al registro electoral por el solo ministerio de la ley, regirán al momento

${ }^{16}$ Cea, J. L., Derecho Constitucional Chileno, Ediciones Universidad Católica de Chile, Santiago, 2008, vol. 1, pp. $323 \mathrm{~s}$.

${ }^{17}$ Esta consideración, ni las que se señalan en la parte final del artículo fueron expuestas por los miembros de la Comisión de Estudios de la Nueva Constitución cuando debatieron y acordaron establecer la obligatoriedad del sufragio (Actas de la Comisión de Estudios de la Nueva Constitución, Sesiones 73 y 74).

${ }^{18}$ El proyecto en el número 3 de su artículo único establece: "Una ley orgánica constitucional contemplará, además, un sistema de registro electoral, bajo la dirección del Servicio Electoral, al que se incorporarán, por el solo ministerio de la ley, quienes cumplan los requisitos establecidos por esta Constitución”. 
de entrar en vigencia la respectiva ley orgánica constitucional a que se refiere el inciso segundo del artículo 18 que se introduce mediante dichas reformas.

Mediante el Mensaje 1440-356, el Presidente de la República ha intentado iniciar la discusión sobre la reforma a la Ley 18.700 sobre Votaciones Populares y Escrutinios y a la Ley 18.556 sobre Sistema de Inscripciones Electorales, presentando un proyecto que modifica la regulación legal en tres aspectos fundamentales: (1) creación de un sistema que implementa la decisión contenida en el Boletín 3544-07 sobre inscripción automática; (2) implementando un sistema que permita el sufragio de los chilenos en el extranjero; y (3) la eliminación de las sanciones para aquellos que no voten, actualizando la ley respecto a la decisión del Boletín 3544-07 de consagrar un sistema de voto voluntario.

La cuestión de la implementación del derecho a sufragio para los chilenos en el extranjero es una cuestión que es espinosa en sus fundamentos y que, además, por el objeto del artículo, no puede ser tratada aquí ${ }^{19}$ Sólo puede apuntarse que tal cuestión, en la que Gobierno y oposición están en desacuerdo, prolongará la discusión sobre el sistema de registro de una manera previsible. Eso hace dudar, como se planteó en la introducción, de la sinceridad del acuerdo sobre el voto voluntario, que aparece más como un compromiso dilatorio que como un acuerdo de principios.

\section{Análisis de la reforma}

Es interesante revisar los fundamentos del proyecto de ley que se dirigen a justificar la implementación el sistema de voto voluntario e inscripción automática. Son mencionados tres de ellos en el mensaje, que pueden ser llamados (1) conceptual; (2) de la participación; y (3) de los costos del sufragio.

El argumento conceptual no es más que la exigencia de sincerar la naturaleza del sufragio como un derecho, eliminando la referencia a su carácter obligatorio:

El sufragio es, por naturaleza, un derecho ciudadano, al igual que la opción a cargos públicos de elección popular, cuestión por lo demás reconocida en el inciso segundo del artículo 13 de nuestra Carta Fundamental (Mensaje 1440-356, Boletín 6418-07).

Este argumento, como se mostró en la primera parte de este trabajo, no tiene fundamento jurídico razonable. Las actuales disposiciones de la Constitución que consagran un derecho (art. 13) obligatorio (art. 18) son perfectamente coherentes. No existen,

${ }^{19}$ Sin embargo, debe hacerse una mención a la incoherencia de la concesión del derecho a sufragio a ciudadanos extranjeros, por la razón de avecindarse en el territorio del Estado y extenderlo a aquellos que dejan dicho territorio. Tal desajuste permite preguntarse cuál es el principio que subyace a la regulación jurídica de la concesión de la titularidad del sufragio, si uno de base nacional o uno pragmático basado en la residencia. 
como ha intentado demostrarse, buenas razones para una reforma en la apelación al argumento conceptual.

El argumento de la participación debe ser tenido en cuenta y considerado con mayor detalle. El aumento de la participación electoral es lo que la reforma busca incentivar. El sistema de sufragio obligatorio e inscripción voluntaria, desde 1989 hasta 2008 ha llevado a una tendencia a la disminución de la participación en las elecciones. Ante ese escenario, y sobre la base de que existen razones de principio (que no se explicitan más allá del argumento conceptual ya refutado) acerca de que el sufragio debe ser voluntario, el argumento de la participación parece concluir que si el voto es voluntario, la inscripción debe ser automática.

En la discusión pública que trató acerca del argumento de la participación aparecieron dos propuestas de modificación del sistema voto obligatorio-inscripción voluntaria que mostraron más respaldo entre los partidos políticos. La primera, que fue desechada en el proyecto de reforma aprobado por el Congreso, consistía en continuar con el voto obligatorio y modificar el sistema de inscripción a uno automático. La segunda, que finalmente fue recogida en el proyecto, consistía en transformar el voto en voluntario y la inscripción en automática. Como se puede advertir, sin necesidad de recurrir a las estadísticas comparadas de participación que también avalan el punto, se prefirió el sistema voluntario-automático que no garantiza un flujo de participación electoral como sí lo garantiza un sistema obligatorio-automático. La razón para preferir un sistema a otro no puede fundarse únicamente en el argumento de la participación, necesita una referencia a razones de principio que exijan que el sufragio tenga el carácter de voluntario. Ello no parece encontrarse en el argumento conceptual, ni en el argumento de la participación. Entonces, parece necesario buscar esa razón de principio en el último de los argumentos presentados en el mensaje.

El argumento de los costos del sufragio es un argumento que puede ser presentado de dos formas. La más insulsa de las dos, parece ser la que adopta estratégicamente el mensaje. Ella es explicada de la siguiente manera:

[...] la necesidad de tener que inscribirse en los Registros Electorales eleva los costos del acto de votar.

En efecto, el sistema que opera en la actualidad [...] eleva para el ciudadano el costo personal del acto eleccionario contribuyendo a desmotivar la participación electoral. En este contexto, mecanismos de inscripción electoral como el nuestro van en contra del espíritu de la Constitución, que en su artículo $1^{\circ}$ señala que el Estado debe asegurar el derecho de las personas a participar con igualdad de oportunidades en la vida nacional. Además, entraba el ejercicio de la ciudadanía.

Para los ciudadanos resulta demasiado costoso inscribirse en los registros electorales. Luego, con el sistema voluntario-automático no tendrán que hacer esfuerzo alguno más que concurrir el día de la elección a sufragar, cuando así lo quieran. El obligar a los ciudadanos a realizar ese esfuerzo no está de acuerdo con la Constitución, señala -abundando- el mensaje. 
Una segunda lectura, que podría tildarse de más filosófica, trata sobre los principios que subyacen a la idea de considerar que la inscripción y el voto son un costo para los ciudadanos. Dichos principios son no sólo la base para sostener el argumento del costo del sufragio, sino que cumplen también el rol de las razones de principio que permiten justificar la reforma frente a la insuficiencia de los argumentos conceptual y de la participación, más arriba revisados.

\section{Sobre los fundamentos: voluntario y obligatorio}

En la base de la idea de que no es lícito exigir la participación obligatoria está una concepción monolíticamente liberal del significado de la relación entre el individuo y el Estado. Para esta concepción, los individuos votan porque es una instancia que les permite influir en la construcción de las reglas que limitarán su libertad. En esos términos, el sufragio es un derecho que mira exclusivamente el beneficio de los individuos, una ventaja. Esto lleva a concluir que el ejercicio del derecho tiene que ser voluntario. Una concepción tal concluye que el Estado no puede imponer cargas a los individuos sino cuando ellas son necesarias para que el funcionamiento del Estado proteja la libertad individual. La protección de la libertad individual, entendida como libertad negativa, está en la base del fundamento del Estado.

La consecuencia necesaria de esta idea es que los individuos, en el momento que participan en la elección, asumen un rol de electores racionales. Se extrapolan así las herramientas del comportamiento económico al comportamiento político y se transforma al elector en un consumidor de políticas públicas.

La concepción de la relación política entre los individuos y el Estado que subyace al modelo del voto obligatorio es una que no tiene problemas con reconocer que el valor de la libertad individual es importante, en la medida que es una restricción que no la afecta de una manera relevante, pero también considera otro factor que está involucrado en el sufragio, que dice relación con el carácter democrático del mismo. No sólo la protección de la libertad negativa sino también de la libertad positiva está en el fundamento del orden estatal. El sufragio no es sólo la manifestación de preferencias, que agregadas determinan el producto que debe ser ofrecido. El sufragio es, desde el punto de vista de una democracia, mucho más. ${ }^{20}$ No se puede abundar en este lugar sobre el significado del sufragio en la democracia y las palabras que siguen son sólo un bosquejo de una argumentación que deberá llevarse a cabo en otra oportunidad.

En una democracia representativa el pueblo está llamado a elegir a sus autoridades. Serán éstas las que tomarán las decisiones. Sin embargo, la decisión más importante consiste en determinar quiénes serán esas autoridades y esa decisión está entregada al

${ }^{20}$ En relación al fundamento del orden estatal fundado en una concepción monolíticamente liberal frente a una concepción mixta fundada en la protección de la libertad positiva y negativa, véase, en general, Passerin, A., La Noción del Estado, Ariel, Barcelona, 2001, y Pettit, P., Republicanismo, Paidós, Barcelona, 1999. Puede consultarse sobre la comparación de modelos de votación liberal y republicano, Pettit, P., “Liberalismo y republicanismo”, en Nuevas Ideas Republicanas, Paidós, Barcelona, 2004. 
pueblo. Que todo el pueblo participe en la elección es la forma más importante que tiene cada uno de los ciudadanos de ser igual a los demás ciudadanos. En una democracia todos los ciudadanos tienen derecho a voto. Así es como todos ellos son iguales en términos políticos. Esto se ha explicado diciendo: un ciudadano igual un voto.

Si todos los ciudadanos son iguales en términos políticos, la elección de las autoridades del Estado debe ser realizada por todos ellos. Cuando la mayoría no es la que decide, parece ser que la opinión de unos vale más que la de otros y que no todos los ciudadanos son iguales en términos políticos. De igual manera, la igualdad política se ve afectada si uno de los ciudadanos no concurre a votar, ya porque un tercero le impide hacerlo, ya porque el propio ciudadano no está interesado en hacerlo, por desinterés. Así, cuando un ciudadano no concurre a votar, su voluntad no cuenta para conformar la voluntad colectiva que toma las decisiones. Lo que pasa entonces es: un ciudadano igual cero voto.

Una comunidad política democrática tiene un legítimo interés en proteger la forma de vida democrática que se funda en la idea de la igualdad política. Así, la obligatoriedad del voto puede ser justificada, por ejemplo, en la necesidad de salvaguardar un sistema de legitimación de las autoridades estatales que considere la opinión igual de cada uno de los ciudadanos.

Primero, porque consideramos que la democracia es la primera y más perfecta forma de garantizar la libertad, entendida no sólo como ausencia de interferencia sino también como ausencia de dominación. Segundo, porque para mantener vigente la idea de que la comunidad es una comunidad de iguales que busca su libertad respecto de individuos, grupos e ideas, se requiere que la participación en la vida pública sea robustecida.

Si puede aceptarse que una comunidad democrática tiene un legítimo interés de proteger su fundamento político, esto es, tiene la posibilidad de protegerse frente a la indiferencia, podrá verse cómo el sistema de voto obligatorio parecía un canal para el logro de ese objetivo. Lo hacía, claro, afectando la libertad individual de permanecer en casa o de pasar un fin de semana en la playa, esto es, de una manera insignificante. ${ }^{21} \mathrm{Al}$ garantizar la comprensión de la igualdad política, sin embargo, se garantiza algo mucho más importante, se garantiza la base sobre la cual esas y todas las demás libertades se construyen en una democracia. ${ }^{22}$

${ }^{21}$ Sobre lo insignificante que es la afectación de la libertad de no votar, puede encontrarse una discusión interesante en Chuaqui, T., "Participación electoral obligatoria: una defensa" y Sierra, L., "El voto como derecho: una cuestión de principios", en op. cit. en nota 2. Sin embargo, la libertad del ciudadano de expresar su opinión política a través de la negación radical al procedimiento de decisión es la que presenta más problemas. Dicha libertad comunicativa, sin embargo, no justifica por sí sola la modificación del voto voluntario, sino sólo una adecuación para que dicha libertad pueda expresarse.

22 Pueden encontrarse numerosos argumentos adicionales para defender la obligatoriedad del voto en Chuaqui, T., op. cit. 


\section{BIBLIOGRAFÍA}

Aldunate, E. "El Fin de la Transición. Hacia una Constitución de Poca Importancia. Visión Crítica de la Reforma de la Ley $\mathrm{N}^{\circ}$ 20.050", en Reforma Constitucional, Ed. LexisNexis, Santiago, 2005.

Alexy, R., Teoría de los Derechos Fundamentales, Centro de Estudios Constitucionales, Madrid, 1993.

Atria, F., Mercado y Ciudadanía en la Educación, Ed. Flandes Indiano, Santiago, 2007.

CEA, J. L., Derecho Constitucional Chileno, $2^{\mathrm{a}}$ ed., Ediciones Universidad Católica de Chile, Santiago, Vol. 1, 2008.

Chunqui, T., "Participación Electoral Obligatoria: Una Defensa", Modernización del Régimen Electoral Chileno, PNUD, Santiago, 2005.

Fontaine, A., Larroulet, C., Viera-Gallo, J. A. y Walker, I. eds. Modernización del Régimen Electoral Chileno, PNUD, Santiago, 2005.

Fuentes y VIllar, eds. Voto Ciudadano. Debate sobre la Inscripción Electoral, FLACSO, Santiago, 2005.

Hohfeld, W.N. Conceptos Jurídicos Fundamentales, Centro Editor de América Latina, Buenos Aires, 1968.

Huneeus, C., ed. La Reforma. El Sistema Binominal en Chile. Propuestas para el Debate, Catalonia, Santiago, 2006.

Passerin, A., La Noción del Estado: Una Introducción a la Teoría Política, Ariel, Barcelona, 2001.

Petтit, P., "Liberalismo y republicanismo", en Nuevas Ideas Republicanas, Paidós, Barcelona, 2004.

Pettit, P., Republicanismo, Paidós, Barcelona, 1999.

Ramos, R., Derecho de Familia, 1ª ed., Ed. Jurídica de Chile, Santiago, 2005.

Schmitt, C., Teoría de la Constitución, Alianza, Madrid, 1983.

Sierra, L. "El Voto como Derecho: Una Cuestión de Principios", en Modernización del Régimen Electoral Chileno, PNUD, Santiago, 2005. 